\title{
Aquisição de encontros consonantais: uma análise de dados naturais e experimentais
}

\author{
Acquisition of consonantal clusters: an analysis of natural and experimental data
}

Thais Telles Barbieri', Giovana Ferreira-Gonçalves ${ }^{2}$

Mestranda em Letras da Universidade Federal de Pelotas. Bolsista CAPES.

Doutora em Letras pela Pontifícia Universidade Católica do Rio Grande do Sul. Docente na Universidade Federal de Pelotas. Bolsista de Produtividade do CNPq.

E-mail: giovanaferreiragoncalves@gmail.com
RESUMO: Neste trabalho, analisa-se o processo de aquisição dos encontros consonantais tautossilábicos em produções orais de crianças falantes do português brasileiro (PB), com idades entre 1:4 e 5:0 (anos:meses). A aquisição da estrutura CCV tem sido foco de investigação em algumas pesquisas, mas, em boa parte desses estudos, etapas intermediárias de aquisição, identificadas por meio de análises acústicas, não são reportadas. Em trabalhos mais recentes, nos quais a análise acústica desempenha importante papel, identifica-se a existência dessas etapas intermediárias, as quais são evidenciadas pela presença de contrastes encobertos. Busca-se, assim, neste artigo: (i) fazer uma descrição de etapas intermediárias presentes na produção de encontros consonantais, (ii) verificar o emprego do alongamento vocálico enquanto mecanismo de distinção entre sílabas CCV e CV e (iii) verificar se o emprego da aspiração de oclusivas também cumpre função distintiva. Foram analisados dados de fala naturais, gravados em interação entre criança e cuidador, e experimentais, coletados em cabine acústica. Esses dados foram submetidos à análise acústica juntamente a palavras sem encontros consonantais e, por meio da comparação entre medidas acústicas - duração absoluta e duração relativa -, encontraram-se indícios do uso de alongamento vocálico e de aspiração enquanto mecanismos distintivos no processo de aquisição da estrutura CCV.

Palavras-chave: Aquisição fonético-fonológica; Encontros consonantais; Fonética acústica.

ABSTRACT: This work analyzes the process of acquisition of tautosyllabic consonantal clusters in oral productions of child speakers of Brazilian Portuguese (BP), aged between 1:4 and 5:0 (years:months). The acquisition of the CCV structure has been a focus of investigation in some researches: however, in many of these studies, intermediate steps, which are identified through acoustic analyses, are not reported. In more recent works, in which acoustic analysis has an important role, these intermediate steps are identified and evidenced by the presence of covert contrasts. Hence, in this paper it is intended to (i) describe intermediate steps present in the production of consonantal clusters, (ii) verify the use of vowel lengthening as a means of distinction between CCV and CV syllables and (iii) verify whether the use of the aspiration of plosives would also have a distinctive function. The data analyzed in this study were collected in natural and experimental contexts. These data have undergone an acoustic analysis along with words without consonantal clusters, considering measures of absolute and relative duration. Through the comparison of segment lengths, evidence has been found that vowel lengthening and the aspiration of plosives may work as means of distinction in the process of acquisition of the CCV structure.

Keywords: Phonetic-phonological acquisition; Consonantal clusters; Acoustic phonetics. 


\section{Introdução}

Teste trabalho, analisa-se o processo de aquisição de encontros consonantais tautossilábicos nas produções de seis crianças falantes do português brasileiro (PB), com idades entre 1:4 e 5:0. Esses encontros consonantais se constituem, no português, de uma obstruinte e de uma líquida. A consoante obstruinte do encontro pode ser uma das seis oclusivas (/p/, /b/, /t/, /d/, /k/ ou /g/) ou uma fricativa labiodental (/f/ ou /v/), enquanto a consoante líquida pode ser lateral (/l/) ou não lateral $(/ \mathrm{r} /)$.

O processo de aquisição dos encontros consonantais é tema já investigado na literatura, sendo descrito em trabalhos como Teixeira (1985), Lamprecht (1990), Ribas (2002, 2004), Ferreira-Gonçalves (2004). A maior parte dos trabalhos mostra a possibilidade de aplicação de diferentes estratégias de reparo no curso da aquisição. No entanto, a constatação dos fenômenos ocorridos na fala infantil se dá especificamente por meio de uma análise de outiva, assim como os modelos teóricos utilizados frequentemente propõem representações categóricas e estágios de aquisição que apresentam gradualidade apenas no aumento da quantidade de produções corretas ao longo do processo (BARBIERI e FERREIRA-GONÇALVES, 2014).

Também, em significativa parte da literatura sobre o tema, as etapas normalmente consideradas na aquisição são apenas duas: uma de produção $\mathrm{C}_{1} \mathrm{~V}$ e outra de produção CCV (RIBAS, 2004). Na primeira, tem-se a realização da obstruinte, mas a líquida não é produzida - a palavra "prato", por exemplo, cuja sílaba complexa seria produzida como [pra], tem sua líquida omitida, sendo produzida como [pa], resultando em ['pa.tu]. Na segunda, o encontro consonantal já está adquirido e a estrutura silábica é produzida com ambos os elementos consonantais, correspondendo à forma-alvo ['pra.tu]. A ilustração desse exemplo se encontra na Fig. 1.
Figura 1 - Etapas do processo de aquisição da estrutura silábica CCV, conforme Ribas (2004)

$$
\begin{aligned}
\mathrm{C}_{1} \mathrm{~V} & \rightarrow \mathrm{CCV} \\
{[\text { 'pa.tu }] } & \rightarrow[\text { 'pra.tu }]
\end{aligned}
$$

Trabalhos mais recentes, como Miranda (2007) e Miranda e Silva (2011), têm abordado a aquisição de encontros consonantais em início de sílaba considerando a existência de contrastes encobertos. Em Miranda e Silva (2011), adota-se uma perspectiva multirrepresentacional ${ }^{1}$ no tratamento dos dados, apontando-se o estabelecimento de contrastes por meio da duração vocálica. Esses trabalhos têm apontado diferentes caminhos no percurso da aquisição, com auxílio especial da análise acústica para tratamento dos dados. Assim, no presente artigo, busca-se reforçar a presença de contrastes encobertos defendida por esses trabalhos, e, consequentemente, contribuir para um entendimento mais detalhado acerca do processo de aquisição dos encontros consonantais.

O objetivo geral deste trabalho, portanto, é investigar a presença de contrastes encobertos nas etapas iniciais do processo de aquisição dos encontros consonantais. Busca-se, mais especificamente: (i) fazer uma descrição de etapas intermediárias presentes na produção de encontros consonantais; (ii) verificar o emprego de alongamento vocálico enquanto mecanismo de distinção entre sílabas CCV e CV no processo de aquisição e (iii) verificar se o emprego da aspiração de oclusivas também cumpre essa mesma função distintiva. Para tanto, a análise acústica desempenha importante função no tratamento dos dados.

Utilizando-se a Fonologia de Usos (BYBEE, 2001) e o Modelo de Exemplares (PIERREHUMBERT, 2000) 
Nas seções seguintes, tratar-se-á da metodologia empregada neste trabalho e dos resultados com a respectiva discussão, encerrando-se com as conclusões.

\section{Metodologia}

A metodologia do trabalho consistiu, primeiramente, na escuta de 31 coletas de áudio pertencentes ao banco de dados de Souza (2015), correspondentes à fala espontânea de quatro crianças, duas do sexo feminino e duas do sexo masculino. Os dados são longitudinais, tendo sido coletados mensalmente pelos cuidadores das crianças por um período mínimo de seis meses $^{2}$, com a utilização de um gravador de voz digital Olympus WS-700m. Nas coletas, há situações de interação entre as crianças e seus cuidadores, incluindo a nomeação espontânea de figuras, com base no instrumento Avaliação Fonológica da Criança (YAVAS et al., 1991). A relação dos sujeitos selecionados - aleatoriamente em cada faixa de idade - se encontra no Quadro 1.

Quadro 1 - Relação dos sujeitos analisados do banco de dados Souza (2015)

\begin{tabular}{|l|c|c|c|c|}
\hline \multicolumn{4}{|c|}{ Sujeitos: banco de dados Souza (2015) } \\
\hline Localidade & S1 & S2 & S3 & S4 \\
\hline $\begin{array}{l}\text { Vista Alegre } \\
\text { do Prata } \\
\text { (período das coletas) }\end{array}$ & $\begin{array}{c}\text { Vista Alegre } \\
\text { do Prata }\end{array}$ & $\begin{array}{c}\text { Vista Alegre } \\
\text { do Prata }\end{array}$ & Porto Alegre \\
\hline Gênero & $1: 4-2: 1$ & $1: 7-2: 0$ & $1: 9-2: 6$ & $2: 3-2: 8$ \\
\hline Coletas por criança & 10 & Feminino & Masculino & Masculino \\
\hline
\end{tabular}

2 O banco de dados de Souza (2015) seguiu metodologia utilizada para a composição do banco LIDES
- Linguagem Infantil em Desenvolvimento -, disponível para consulta no Laboratório Emergência da - Linguagem Oral (LELO) da Universidade Federal de Pelotas.
Por meio da escuta dos áudios, foi feito, para cada coleta, o levantamento de todos os vocábulos contendo encontros consonantais tautossilábicos, os quais foram transcritos foneticamente com base em outiva. Assim, foram considerados todos os vocábulos contendo sílabas com estrutura CCV (ex.: fe $\underline{\text { bre }}$, quatro, livro) e outras variações, tais como CCVC (ex.: três, $\underline{\text { brincar) }}$ e CCVV (ex.: a $\underline{\text { briu }}$ ). Após a transcrição, os dados foram classificados um a um conforme diferentes categorias. Essas categorias são relativas ao contexto linguístico em que a sílaba se encontrava e aos tipos de produções realizadas na fala ${ }^{3}$. A relação de fatores para classificação, com suas subcategorias e respectivos códigos, se encontra no Quadro 2. Os grupos 1 a 5 dizem respeito ao nível silábico; os grupos 6 a 9, ao nível segmental. Também, os grupos em células preenchidas dizem respeito ao contexto linguístico em que a sílaba se encontra, enquanto os grupos em células hachuradas se relacionam às substituições realizadas na fala da criança.

Os dados foram contabilizados conforme os diferentes fatores apresentados no Quadro 2. Com base na contagem, foram elaboradas planilhas, contendo resultados mensais bem como totais, para cada criança, para que se tivesse um mapeamento do processo de aquisição da estrutura CCV e das principais estratégias de reparo utilizadas individualmente e em diferentes estágios desse processo. 
Quadro 2 - Relação de variáveis dependentes e independentes controladas para a codificação dos dados

\begin{tabular}{|c|c|c|c|c|c|c|c|c|c|c|}
\hline Grupo & \multicolumn{10}{|c|}{ Variáveis dependentes e independentes } \\
\hline \multirow{2}{*}{1} & \multicolumn{10}{|c|}{ Produção do onset complexo } \\
\hline & \multicolumn{5}{|c|}{ Não realizada } & \multicolumn{5}{|c|}{ Realizada } \\
\hline \multirow{2}{*}{2} & \multicolumn{10}{|c|}{ Acento da sílaba } \\
\hline & \multicolumn{3}{|c|}{ Pré-tônica } & \multicolumn{4}{|c|}{ Tônica } & \multicolumn{3}{|c|}{ Pós-tônica } \\
\hline \multirow{2}{*}{3} & \multicolumn{10}{|c|}{ Posição da sílaba na palavra } \\
\hline & \multicolumn{3}{|c|}{ Inicial } & \multicolumn{4}{|c|}{ Medial } & \multicolumn{3}{|c|}{ Final } \\
\hline \multirow{2}{*}{4} & \multicolumn{10}{|c|}{ Padrão da sílaba } \\
\hline & \multicolumn{2}{|c|}{$\mathrm{CCV}$} & \multicolumn{2}{|c|}{ CCVC } & \multicolumn{2}{|c|}{ CCVCC } & \multicolumn{2}{|r|}{ CCVV } & \multicolumn{2}{|r|}{ CCVVC } \\
\hline \multirow[b]{2}{*}{5} & \multicolumn{10}{|c|}{ Padrão da sílaba: substituições } \\
\hline & $\mathrm{V}$ & $\mathrm{CV}$ & $\mathrm{CCV}$ & $\mathrm{CVV}$ & VC & $\mathrm{VV}$ & CVC & CVCV & $\varnothing$ & $\begin{array}{l}\text { prod. } \\
\text { Gradiente }\end{array}$ \\
\hline \multirow{2}{*}{6} & \multicolumn{10}{|c|}{ Segmentos que constituem o onset complexo: primeiro elemento } \\
\hline & $/ \mathrm{p} /$ & & & $/ \mathrm{t} /$ & /d/ & $/ \mathrm{k}$ & & /g/ & /f/ & $/ \mathrm{v} /$ \\
\hline \multirow{2}{*}{7} & \multicolumn{10}{|c|}{ Segmentos que constituem o onset complexo: segundo elemento } \\
\hline & \multicolumn{5}{|c|}{ /l/ } & \multicolumn{5}{|c|}{$/ r /$} \\
\hline \multirow{2}{*}{8} & \multicolumn{10}{|c|}{$\begin{array}{l}\text { Segmentos que constituem o onset complexo: primeiro elemento } \\
\text { Substituições }\end{array}$} \\
\hline & $\begin{array}{c}\text { sem } \\
\text { subst. }\end{array}$ & {$[\mathrm{p}]$} & [b] & {$[\mathrm{t}]$} & [d] & {$[\mathrm{k}]$} & {$[\mathrm{g}]$} & outra & $\varnothing$ & $\begin{array}{c}\text { prod. } \\
\text { Gradiente }\end{array}$ \\
\hline \multirow{2}{*}{9} & \multicolumn{10}{|c|}{$\begin{array}{l}\text { Segmentos que constituem o onset complexo: segundo elemento } \\
\text { Substituições }\end{array}$} \\
\hline & $\begin{array}{c}\text { sem } \\
\text { subst }\end{array}$ & & & $/$ г/ & {$[\mathrm{w}]$} & {$[y$} & & outra & $\varnothing$ & $\begin{array}{c}\text { prod. } \\
\text { Gradiente }\end{array}$ \\
\hline
\end{tabular}

A etapa seguinte foi a análise acústica por meio do programa Praat (BOERSMA e WEENINK, 2016), já que, por meio da outiva dos dados, verificaram-se dados com indícios de possíveis casos de alongamento vocálico e aspiração de oclusivas iniciais. Para cada caso de alongamento e de aspiração, foram procuradas palavras sem encontros consonantais em contextos linguísticos similares, palavras cuja sílaba CV tivesse mesma tonicidade, mesma vogal e mesma sonoridade de obstruinte (por exemplo, para a análise da palavra bruxa, a qual contém sílaba CCV, foi necessária a comparação com produções da palavra $D u d a$, em que a sílaba [du] também é tônica, possui obstruinte sonora e vogal $[\mathrm{u}]$ ). Para as palavras com sílabas CCV e CV analisadas, foram realizadas as medidas de duração absoluta e de duração relativa das palavras, das sílabas e dos segmentos (segmento vocálico nos casos de alongamento e segmento consonantal nos casos de aspiração).

Num segundo momento, para que se tivesse dados de produção de crianças de idades mais avançadas, foram realizadas coletas de dados de fala de duas crianças, com idades de 3:6 e 5:0. As duas coletas - uma para cada criança - foram realizadas no Laboratório Emergência da Linguagem Oral (LELO), situado no Centro de Letras e Comunicação (CLC) da Universidade Federal de Pelotas (UFPel). Para que a participação das crianças fosse possível, os responsáveis leram e assinaram um Termo de Consentimento Livre e Esclarecido. Os dados dos sujeitos participantes da coleta se encontram no Quadro 3:

Quadro 3 - Relação dos sujeitos da coleta experimental

\begin{tabular}{|l|c|c|}
\hline \multicolumn{3}{|c|}{ Sujeitos: localidade e faixa etária } \\
\hline Localidade & S5 & S6 \\
\hline Idade & Rio Grande & Pelotas \\
\hline Gênero & $3: 6$ & $5: 0$ \\
\hline Coletas por criança & Masculino & Masculino \\
\hline
\end{tabular}

As coletas tiveram como finalidade a produção de pares de palavras cuja diferenciação era a presença ou ausência de encontro consonantal. A relação de palavras, baseada em conjunto proposto por Vassoler (2016), encontra-se no Quadro 4: 
Quadro 4 - Pares mínimos para produção nas coletas

\begin{tabular}{|l|l|l|l|}
\hline prato & pato & preso & peso \\
\hline grato & gato & frita & fita \\
\hline branco & banco & frota & foto \\
\hline prego & pego & broa & boa \\
\hline pressa & peça & bruxa & bucha \\
\hline
\end{tabular}

As coletas ocorreram no Laboratório Emergência da Linguagem Oral (LELO), situado no Centro de Letras e Comunicação (CLC) da Universidade Federal de Pelotas (UFPel), e foram compostas de duas etapas. Na primeira, as crianças passaram por um processo de familiarização com as palavras por meio de uma interação com exibição de figuras, as quais se vinculavam ao conceito das palavras a serem produzidas. Na Figura 2, encontram-se duas das 20 imagens utilizadas. Nessa primeira etapa, a interação entre criança, cuidador e pesquisador foi gravada em áudio para que se tivesse um banco adicional de produções dessas crianças.

Figura 2 - Imagens correspondentes às palavras prato e pato

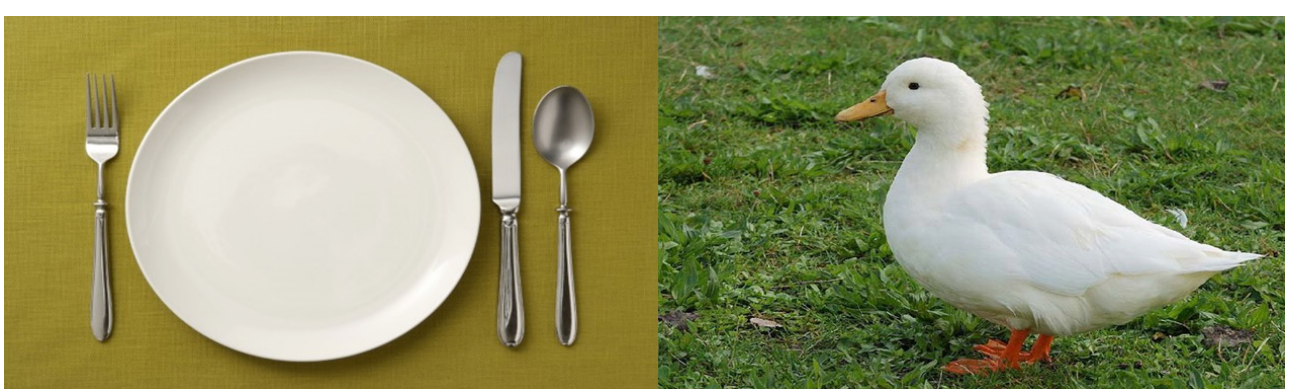

Após a etapa de familiarização, foi realizada, em cabine acústica, a gravação simultânea de áudio e imagens ultrassonográficas das produções das 20 palavras. $\mathrm{O}$ áudio foi capturado com um gravador Zoom, modelo H4N, enquanto as imagens ultrassonográficas foram capturadas com um aparelho de ultrassom Mindray, modelo DP 6600, com um transdutor acoplado. Para a coleta integrada de áudio e ultrassom, utilizou-se o software $A A A$ (Articulate Assistant Advanced, versão 2.14).

Para a análise acústica das gravações de áudio, utilizou-se o programa Praat (BOERSMA E WEENINK, 2016), versão 6.0.174.

\section{Resultados e discussão}

Por meio da escuta dos áudios, foram encontradas 580 palavras com encontro consonantal, mas as produções efetivas desse encontro pelas crianças foram apenas três - realizadas por S4, o sujeito com a faixa etária mais avançada. A relação da quantidade de possibilidades de produção e realizações efetivas de encontro consonantal para cada uma das crianças pode ser vista na Tabela 1.

Tabela 1 - Total de possibilidades e ocorrências da estrutura silábica CCV nos dados analisados

\begin{tabular}{cccc}
\hline Sujeitos & Possibilidades & Produções & $\begin{array}{c}\text { Estratégias de } \\
\text { reparo }\end{array}$ \\
S1 & 122 & 0 & 122 \\
S2 & 65 & 0 & 65 \\
S3 & 71 & 0 & 71 \\
S4 & 322 & 3 & 319 \\
Total & 580 & 3 & 577 \\
\hline
\end{tabular}

${ }^{4}$ No presente artigo, apenas os dados acústicos serão analisados. 
Todos os outros 577 casos, nos quais não houve produção completa da estrutura $\mathrm{CCV}$, tiveram alguma estratégia de reparo empregada. A relação das estratégias de reparo adotadas se encontra em (1).

(1) Estratégias de reparo identificadas com base em análise de outiva:

a) $\mathrm{C}_{1} \mathrm{~V}$ : produção da sequência $\mathrm{CV}$, com a preservação da primeira consoante da sílaba CCV (ex.: outro produzida como ['o.to]);

b) $\mathrm{C}_{1 \mathrm{su}} \mathrm{V}$ : produção da sequência $\mathrm{CV}$, com a preservação da primeira consoante da sílaba CCV, mas com processo de desvozeamento (ex.: abre produzida como ['a.pi]);

c) V: produção apenas de uma vogal (ex.: fruteiro produzida como [a.'te.wo]);

d) VV: produção, modificada ou não, da vogal base da sílaba, antecedida por um glide (ex.: cobra produzida como['ko.wo]);

e) $\mathrm{C}^{\mathrm{h} V}$ : produção da sequência $\mathrm{CV}$, com a preservação da primeira consoante da sílaba CCV, produzida de forma aspirada (ex.: preto produzida como ['p $\left.\left.\mathrm{p}^{\mathrm{h}} \mathrm{e} . \mathrm{tu}\right]\right)$;

f) CV: produção da sequência CCV como uma CV:, com vogal alongada (ex.: bruxa produzida como ['bu:.ta]);

g) $\mathrm{C}_{2} \mathrm{~V}$ : produção da sequência $\mathrm{CV}$, com a preservação da segunda consoante da sílaba CCV (ex.: descobrir produzida como [t $\left.\left.\left.\int i . k u . ' r i\right]\right]\right) ;$

h) CwV: produção da sequência CVV, com a realização da líquida como glide (ex.: brigo produzida como ['bwi.gu]);

i) ClV: produção da sequência CCV, com a realização do rótico como líquida lateral (ex.: febre produzida como ['fe.bli]);

j) Produções gradientes: produções não especificadas por meio do alfabeto fonético internacional;

k) ø: omissão total da sílaba CCV (ex.: dragão produzida como ['gãw]).

Na Tabela 2, a estratégia de reparo mais empregada foi a de produção $\mathrm{C}_{1} \mathrm{~V}$, a qual consiste em uma não realização da líquida com manutenção do primeiro elemento consonantal. A estratégia de produção $\mathrm{C}_{1} \mathrm{~V}$ foi encontrada em mais de $80 \%$ dos dados, o que corresponde ao apontado por estudos anteriores, como Ribas $(2002,2004)$ e Bonilha (2004). Em idades menos avançadas, como 1:8 (S1), 1:11 (S2) e 2:0 (S2), foram encontradas produções que continham não só a omissão da líquida, mas também uma substituição do primeiro elemento consonantal em relação à sonoridade ou ao modo de articulação (sinalizadas na Tab. 3 como $\mathrm{C}_{1 \mathrm{su}} \mathrm{V}$ ).

Tabela 2 - Estratégias de reparo adotadas e respectivas porcentagens em relação ao total de dados analisados

\begin{tabular}{lcc}
\hline $\begin{array}{l}\text { Tipo de estratégia } \\
\text { de reparo }\end{array}$ & Número de ocorrências & $\%$ \\
\hline $\mathrm{C}_{1} \mathrm{~V}$ & 471 & 81,62 \\
$\mathrm{C}_{1 \text { su }} \mathrm{V}$ & 53 & 9,18 \\
$\mathrm{~V}$ & 9 & 1,55 \\
$\mathrm{VV}$ & 5 & 0,86 \\
$\mathrm{C} \mathrm{h} V$ & 4 & 0,69 \\
$\mathrm{CV}:$ & 4 & 0,69 \\
$\mathrm{C}$ V V & 1 & 0,17 \\
$\mathrm{CwV}$ & 1 & 0,17 \\
$\mathrm{ClV}$ & 1 & 0,17 \\
produções gradientes & 26 & 4,50 \\
$\varnothing$ & 6 & 1,03 \\
Total & $\mathbf{5 7 7}$ & $\mathbf{1 0 0}$ \\
\hline
\end{tabular}

Também foram encontradas outras estratégias já constatadas em trabalhos como Ribas (2004), como a semivocalização da líquida (CwV), a substituição do rótico pela consoante lateral (CIV) e a produção exclusiva da segunda consoante da sequência $\left(\mathrm{C}_{2} \mathrm{~V}\right)$. No entanto, essas estratégias figuraram de forma pouco expressiva, tendo, na totalidade dos dados, apenas uma ocorrência cada. 
Quanto às produções efetivas do encontro consonantal, constatou-se que a primeira produção completa do encontro consonantal ocorreu aos 2:5, mas com substituição do rótico pela lateral. Isso pode corresponder a uma fase que antecederia a de aquisição completa, já que, embora a criança tenha se tornado, em certa idade, capaz de articular suas primeiras estruturas complexas, essa produção ainda está sujeita a reajustes, principalmente no segundo elemento consonantal. Isso pode estar relacionado a uma tentativa de conciliar os diferentes gestos envolvidos nas sequências produzidas, assim como ao complexo processo de aquisição de [r].

Com base em outiva, dentre as produções do tipo $C_{1} V$, três foram selecionadas por indiciarem um possível emprego do alongamento vocálico. Essas palavras foram comparadas a palavras com sílabas sem encontro consonantal, isto é, com estrutura $\mathrm{CV}$, em contextos linguísticos similares. A palavra com sílaba CV deveria possuir, na sílaba analisada, a mesma tonicidade, a mesma vogal e uma obstruinte com mesma sonoridade e modo de articulação. 0 objetivo era verificar se a duração da vogal constituiria mecanismo de distinção entre tipos silábicos. Na Tabela 3, tem-se a relação das produções CCV e CV, com medidas de duração da palavra e da vogal (duração absoluta e relativa).

$\mathrm{Na}$ Tab. 3, as células hachuradas indicam medidas em palavras CV menores que as encontradas nas CCV. Na produção CCV para o alvo bruxa, de S1, tem-se menor duração absoluta da vogal tônica em todas as palavras com sílabas CV; também, a duração relativa é menor em três das quatro palavras. Este conjunto de dados mostra uma diferença expressiva e consistente, o que indicia um possível mecanismo de distinção.

No entanto, ainda de acordo com a Tab. 3, na palavra braba, também de S1, as produções CV que apresentam durações menores são duas, além de não serem as mesmas em termos de duração absoluta e relativa. Em prato, palavra produzida por S4, também tem-se menor duração em apenas duas palavras com CV, e menor duração relativa em apenas uma. A menor expressividade nas diferenças de duração nesses dois últimos casos faz com que seja necessário investigar se diferenças de duração vocálica atuariam como parte da aquisição específica dos segmentos vocálicos, não como um mecanismo distintivo.

Tabela 3 - Análise da duração da vogal tônica em produções CCV e CV

\begin{tabular}{|c|c|c|c|c|c|c|c|c|c|}
\hline \multirow{2}{*}{ Sujeito } & \multirow{2}{*}{$\begin{array}{l}\text { Ocorrência } \\
\text { CCV }\end{array}$} & \multirow{2}{*}{$\begin{array}{c}\text { Duração } \\
\text { da palavra } \\
\text { (ms) }\end{array}$} & \multicolumn{2}{|c|}{$\begin{array}{l}\text { Duração da } \\
\text { vogal }\end{array}$} & \multirow{2}{*}{ Sujeito } & \multirow{2}{*}{$\begin{array}{c}\text { Ocorrência } \\
\text { CV }\end{array}$} & \multirow{2}{*}{$\begin{array}{c}\text { Duração } \\
\text { da palavra } \\
(\mathrm{ms})\end{array}$} & \multicolumn{2}{|c|}{$\begin{array}{l}\text { Duração da } \\
\text { vogal }\end{array}$} \\
\hline & & & $\begin{array}{l}\text { Abs. } \\
\text { (ms) }\end{array}$ & $\begin{array}{l}\text { Rel. } \\
\text { (\%) }\end{array}$ & & & & $\begin{array}{l}\text { Abs. } \\
\text { (ms) }\end{array}$ & $\begin{array}{l}\text { Rel. } \\
\text { (\%) }\end{array}$ \\
\hline \multirow[t]{8}{*}{ S1 } & \multirow[t]{4}{*}{ bruxa } & \multirow[t]{4}{*}{1084} & \multirow[t]{4}{*}{516} & \multirow[t]{4}{*}{47,60} & \multirow[t]{8}{*}{ S1 } & Duda & 199 & 141 & 70,85 \\
\hline & & & & & & Duda & 680 & 227 & 33,38 \\
\hline & & & & & & Duda & 522 & 209 & 40,03 \\
\hline & & & & & & Duda & 621 & 237 & 38,16 \\
\hline & \multirow[t]{4}{*}{$b r a b a$} & \multirow[t]{4}{*}{906} & \multirow[t]{4}{*}{377} & \multirow[t]{4}{*}{41,61} & & auto (VV) & 1168 & 448 & 38,35 \\
\hline & & & & & & vaca & 534 & 198 & 37,07 \\
\hline & & & & & & galo & 334 & 159 & 47,60 \\
\hline & & & & & & sapo & 927 & 412 & 44,40 \\
\hline \multirow[t]{5}{*}{ S4 } & \multirow[t]{5}{*}{ prato } & \multirow[t]{5}{*}{958} & \multirow[t]{5}{*}{614} & \multirow[t]{5}{*}{64,09} & \multirow[t]{5}{*}{ S4 } & carro & 980 & 643 & 65,61 \\
\hline & & & & & & carro & 486 & 324 & 66,66 \\
\hline & & & & & & mercado & 1448 & 570 & 39,36 \\
\hline & & & & & & carro & 957 & 682 & 71,26 \\
\hline & & & & & & carro & 994 & 663 & 66,70 \\
\hline
\end{tabular}

No entanto, ainda de acordo com a Tab. 3, na palavra braba, também de $\mathrm{S} 1$, as produções $\mathrm{CV}$ que apresentam durações menores são duas, além de não serem as mesmas em termos de duração absoluta e relativa. Em prato, palavra produzida por $\$ 4$, também tem-se menor duração em apenas 
duas palavras com $\mathrm{CV}$, e menor duração relativa em apenas uma. A menor expressividade nas diferenças de duração nesses dois últimos casos faz com que seja necessário investigar se diferenças de duração vocálica atuariam como parte da aquisição específica dos segmentos vocálicos, não como um mecanismo distintivo.

Também foram encontrados quatro casos de possível aspiração de oclusivas. Dois desses dados foram selecionados e, assim como nos casos com possibilidade de alongamento vocálico, comparados a palavras sem encontro consonantal. A palavra com sílaba CV deveria possuir a mesma tonicidade e a mesma obstruinte. A finalidade era semelhante: verificar se a oclusiva em encontro consonantal era aspirada para garantir a marcação temporal de uma líquida ainda não adquirida, distinguindo-se as sílabas CCV das CV por meio desse processo. As produções CCV e CV, com medidas de duração absoluta e relativa das oclusivas, encontram-se na

\section{Tabela 4:}

Tabela 4 - Análise da duração das oclusivas [p] e [k] em produções CCV e CV

\begin{tabular}{|c|c|c|c|c|c|c|c|c|}
\hline \multirow{2}{*}{ Sujeito } & \multirow{2}{*}{$\begin{array}{l}\text { Ocorrência } \\
\text { CCV }\end{array}$} & \multirow{2}{*}{$\begin{array}{c}\text { Duração } \\
\text { da palavra } \\
\text { (ms) }\end{array}$} & \multicolumn{2}{|c|}{$\begin{array}{l}\text { Duração da } \\
\text { oclusiva }\end{array}$} & \multirow{2}{*}{$\begin{array}{c}\text { Ocorrência } \\
\text { CV }\end{array}$} & \multirow{2}{*}{$\begin{array}{c}\text { Duração } \\
\text { da palavra } \\
\text { (ms) }\end{array}$} & \multicolumn{2}{|c|}{$\begin{array}{l}\text { Duração da } \\
\text { oclusiva }\end{array}$} \\
\hline & & & $\begin{array}{l}\text { Abs. } \\
\text { (ms) }\end{array}$ & $\begin{array}{l}\text { Rel. } \\
\text { (\%) }\end{array}$ & & & $\begin{array}{l}\text { Abs. } \\
\text { (ms) }\end{array}$ & $\begin{array}{l}\text { Rel. } \\
\text { (\%) }\end{array}$ \\
\hline \multirow[t]{8}{*}{ S4 } & preto & 1110 & 56 & 5,04 & peixe & 1029 & 27 & 2,62 \\
\hline & & & & & peixinho & 893 & 19 & 2,12 \\
\hline & & & & & peixinho & 1121 & 7 & 0,62 \\
\hline & & & & & pegar & 469 & 19 & 4,05 \\
\hline & criança & 1085 & 114 & 10,50 & cavalo & 565 & 31 & 5,48 \\
\hline & & & & & descobrir & 1385 & 18 & 1,29 \\
\hline & & & & & descobrir & 672 & 14 & 2,08 \\
\hline & & & & & caneta & 776 & 32 & 4,12 \\
\hline
\end{tabular}

Na Tabela 4 as células hachuradas também sinalizam medidas de duração menores em relação às das sílabas CCV. Neste caso, observa-se menor duração, tanto relativa quanto absoluta, das oclusivas de todas as produções CV em relação às das produções CCV. Observe-se que mesmo os dados com a maior duração de oclusiva em CV (como $27 \mathrm{~ms}$ de [p] em peixe) não chegam à metade da duração da oclusiva em CCV (56 ms de $\left[\mathrm{p}^{\mathrm{h}}\right]$ em preto). Da mesma forma, dados com a maior duração relativa em CV (como 5,48\% de [k] de cavalo) no máximo ultrapassam em décimos a metade da duração relativa da oclusiva em CCV $\left(10,50 \%\right.$ de $\left[\mathrm{k}^{\mathrm{h}}\right]$ em criança).

Esses dados indiciam mais fortemente o uso da estratégia de aspiração de oclusivas enquanto mecanismo de distinção, dada a diferença acentuada de durações absoluta e relativa entre sílabas CCV e CV. Ainda assim, faz-se necessário verificar se esse é um fenômeno a ser relacionado, primeiramente, com a aquisição das oclusivas ao invés de com o estabelecimento de distinções entre tipos de sílaba.

Quanto aos dados experimentais, em todos os pares analisados, para os dois informantes, foram constatadas a utilização do alongamento e/ou da aspiração da obstruinte. A hipótese do alongamento vocálico se confirmou nos dados de S5, em que grande parte dos dados apresentou maior duração absoluta da vogal no alvo CCV em relação ao alvo CV. As medidas de duração das vogais e obstruintes produzidas por S5 se encontram na Tabela 5, adiante.

Nos dados de S5, também se confirmou a hipótese da aspiração de oclusivas, com ênfase para os pares preso/peso e broa/boa. Tal estratégia foi verificada, fundamentalmente, nos dados de S6. Nesses dados, houve durações absoluta e relativa maiores em oclusivas em CCV e menores em CV. Os dados de S6, com medidas de vogais e obstruintes, encontram-se na Tabela 6. 
Tabela 5 - Análise da duração de obstruintes e vogais em produções de S5 (3:6)

\begin{tabular}{|c|c|c|c|c|c|c|c|}
\hline \multicolumn{8}{|c|}{ S5 $(3: 6)$} \\
\hline \multirow[b]{2}{*}{ Par } & \multirow{2}{*}{\multicolumn{2}{|c|}{ Palavra }} & \multirow{2}{*}{$\begin{array}{c}\text { Duração } \\
\text { da palavra } \\
\text { (ms) }\end{array}$} & \multicolumn{2}{|c|}{ Duração da obstruinte } & \multicolumn{2}{|c|}{ Duração da vogal } \\
\hline & & & & $\begin{array}{l}\text { Absoluta } \\
\text { (ms) }\end{array}$ & $\begin{array}{l}\text { Absoluta } \\
\text { (ms) }\end{array}$ & $\begin{array}{l}\text { Absoluta } \\
\text { (ms) }\end{array}$ & $\begin{array}{c}\text { Relativa } \\
\text { (\%) }\end{array}$ \\
\hline \multirow[t]{3}{*}{01} & $\mathrm{CCV}$ & prato & 699 & 16 & 2,2 & 475 & 67,9 \\
\hline & & & 668 & 32 & 4,7 & 585 & 87,5 \\
\hline & $\mathrm{CV}$ & pato & 550 & 22 & 4,0 & 198 & 36,0 \\
\hline \multirow[t]{3}{*}{02} & CCV & pressa & 588 & 21 & 3,5 & 272 & 46,2 \\
\hline & & & 749 & 18 & 2,4 & 327 & 43,6 \\
\hline & $\mathrm{CV}$ & peça(s) & 1091 & 26 & 2,3 & 501 & 45,9 \\
\hline \multirow[t]{2}{*}{03} & CCV & preso & 531 & 27 & 5,0 & 303 & 57,0 \\
\hline & $\mathrm{CV}$ & peso & 332 & 8 & 2,4 & 189 & 56,9 \\
\hline \multirow[t]{3}{*}{04} & CCV & frita & 889 & 121 & 13,6 & 426 & 47,9 \\
\hline & $\mathrm{CV}$ & fita & 399 & 115 & 28,8 & 230 & 57,6 \\
\hline & & & 478 & 121 & 25,3 & 277 & 57,9 \\
\hline \multirow[t]{2}{*}{05} & CCV & broa & 769 & 105 & 13,6 & 435 & 56,5 \\
\hline & $\mathrm{CV}$ & boa & 612 & 27 & 4,4 & 228 & 37,2 \\
\hline
\end{tabular}

Tabela 6 - Análise da duração de obstruintes e vogais em produções de S6 (5:0)

\begin{tabular}{|c|c|c|c|c|c|c|c|}
\hline \multirow{4}{*}{$\begin{array}{l}\text { Par } \\
01\end{array}$} & & & \multicolumn{3}{|c|}{ S6 (5:0) } & & \\
\hline & \multirow{2}{*}{\multicolumn{2}{|c|}{ Palavra }} & \multirow{2}{*}{$\begin{array}{c}\text { Duração } \\
\text { da palavra } \\
\text { (ms) }\end{array}$} & \multicolumn{2}{|c|}{ Duração da obstruinte } & \multicolumn{2}{|c|}{ Duração da vogal } \\
\hline & & & & \multirow{2}{*}{$\begin{array}{c}\text { Absoluta } \\
\text { (ms) } \\
21\end{array}$} & \multirow{2}{*}{$\begin{array}{c}\text { Relativa } \\
\text { (\%) }\end{array}$} & \multirow{2}{*}{$\begin{array}{c}\begin{array}{c}\text { Absoluta } \\
\text { (ms) }\end{array} \\
217\end{array}$} & \multirow{2}{*}{$\begin{array}{c}\text { Relativa } \\
\text { (\%) } \\
25,9\end{array}$} \\
\hline & CCV & prato & 836 & & & & \\
\hline & $\mathrm{CV}$ & pato & 474 & 8 & 1,6 & 181 & 38,1 \\
\hline \multirow[t]{3}{*}{02} & CCV & branco & 457 & 99 & 21,6 & 129 & 28,2 \\
\hline & & & 512 & 70 & 13,6 & 173 & 33,7 \\
\hline & CV & banco & 496 & 35 & 7,0 & 258 & 52,0 \\
\hline \multirow[t]{3}{*}{03} & $\mathrm{CCV}$ & pressa & 475 & 26 & 5,4 & 124 & 26,1 \\
\hline & & & 673 & 12 & 1,7 & 249 & 36,9 \\
\hline & $\mathrm{CV}$ & peça & 478 & 45 & 9,4 & 211 & 44,1 \\
\hline \multirow[t]{2}{*}{04} & CCV & frota & 391 & 147 & 37,5 & 88 & 22,5 \\
\hline & $\mathrm{CV}$ & foto & 990 & 163 & 16,4 & 217 & 21,9 \\
\hline \multirow[t]{2}{*}{05} & $\mathrm{CCV}$ & bruxa & 501 & 72 & 14,3 & 109 & 21,7 \\
\hline & $\mathrm{CV}$ & bucha & 362 & 35 & 9,6 & 125 & 34,5 \\
\hline
\end{tabular}

Esses dados apontam a existência de estratégias de reparo diferenciadas no processo de aquisição, ou seja, para S5, o alongamento vocálico indicia-se como distintivo para a oposição das estruturas CCV e CV; para S6, a aspiração da obstruinte se evidencia como mais produtiva para a referida distinção.

\section{Conclusão}

Nesta pesquisa, constataram-se fenômenos já encontrados na literatura. A estratégia $\mathrm{C}_{1} \mathrm{~V}$ foi a mais expressiva nos dados analisados; também, estratégias de reparo outras correspondem às já encontradas na literatura.

No que concerne à amostra de dados naturais, a hipótese do alongamento vocálico se confirmou parcialmente nos dados de S1, constituindo possível mecanismo de distinção entre tipos silábicos. No entanto, é preciso verificar se esse alongamento faria parte do processo específico de aquisição da vogal, considerando-se as medidas de duração relativa constatadas.

Já a hipótese da aspiração de oclusivas, por sua vez, se confirmou nos dados de S4, já que duração absoluta e relativa foram menores em palavras sem encontro consonantal. Ainda assim, se faz necessário um diálogo com a literatura sobre aquisição de oclusivas, para que se verifique se a aspiração não seria um fenômeno particular da aquisição segmental. Faz-se necessário, também, analisar uma maior quantidade de dados, para fins de viabilizar a realização de testes estatísticos.

A análise do segundo banco de dados, composto de coletas experimentais, também aponta a existência de estratégias de reparo diferenciadas na aquisição de CCV. Verificaram-se casos de concomitância dos dois fenômenos e a predominância de uma das estratégias, o que indica possíveis caminhos de aquisição.

Embora as conclusões deste estudo não sejam definitivas, elas reforçam o que tem sido afirmado por trabalhos mais recentes: a importância da 
investigação acústica dos dados, a qual pode indiciar a possibilidade de as crianças escolherem diferentes caminhos no processo de aquisição, recorrendo a estratégias diferenciadas. Também, a acústica pode evidenciar o estabelecimento de distinções fonológicas em etapas mais precoces do que as reportadas pela literatura. Assim, o procedimento da análise acústica se faz necessário para que se tenham uma investigação e uma descrição ainda mais precisas da aquisição fonológica.

\section{Referências}

BARBIERI, Thais Telles; FERREIRA-GONÇALVES, Giovana. Aquisição de encontros consonantais tautossilábicos no português brasileiro: um estudo longitudinal. In: XXIII Congresso de Iniciação Científica UFPel, Pelotas, 2014.

A emergência inicial da estrutura silábica CCV. In: III Encontro Nacional sobre a Linguagem da Criança: saberes em contraponto. Instituto de Letras, UFRGS, 2015a.

Contrastes encobertos na aquisição de encontros consonantais tautossilábicos. In: XXIV Congresso de Iniciação Científica (I Semana Integrada de Ensino, Pesquisa e Extensão). UFPel, 2015b.

Alongamento vocálico e aspiração de oclusivas na aquisição da estrutura silábica CCV. In: XXIV Congresso de Iniciação Científica (Salão Universitário), UCPel, 2015c.

BOERSMA, Paul; WEENINK, David. Praat: doing phonetics by computer. Programa de computador, 2017.

BONILHA, Giovana Ferreira Gonçalves. Aquisição fonológica do português brasileiro: uma abordagem conexionista da Teoria da Otimidade. Tese (Doutorado em Letras) - Instituto de Letras e Artes, Pontifícia Universidade Católica do Rio Grande do Sul, 2004.

BYBEE, Joan. Phonology and language use. Cambridge University Press, 2001.

LAMPRECHT, Regina Ritter. Perfil da aquisição normal da fonologia do Português. Descrição longitudinal de 12 crianças: 2:9 a 5:5. 1990. Tese (Doutorado em Letras) - Instituto de Letras e Artes, Pontifícia Universidade Católica do Rio Grande do Sul, 1990.
MEZZOMO, Carolina Lisbôa; MOTA, Helena Bolli; DIAS, Roberta Freitas; GIACCHINI, Vanessa. O uso da estratégia de alongamento compensatório em crianças com desenvolvimento fonológico normal e desviante. Letras de Hoje, Porto Alegre, v. 43, n. 3, p. 35-41, 2008.

MIRANDA, Isabel Cristina Campolina. Aquisição e variação estruturada de encontros consonantais tautossilábicos. 2007. Tese (Doutorado em Linguística) - Programa de Pós-Graduação em Estudos Linguísticos. Universidade Federal de Minas Gerais, 2007.

MIRANDA, Isabel Cristina Campolina; SILVA, Thaïs Cristófaro. Aquisição de encontros consonantais tautossilábicos: uma abordagem multirrepresentacional. Revista Lingüística, v. 7, n. 1, 2011.

PIERREHUMBERT, Janet. Exemplar Dynamics: Word frequency, lenition and contrast. In: BYBEE, J.; HOPPER, P. (Ed.). Frequency and the emergence of linguistic structure. Amsterdam: Benjamins, 2000

RIBAS, Letícia Pacheco. Aquisição do onset complexo. 2002. Dissertação (Mestrado em Letras) - Instituto de Letras e Artes, Pontifícia Universidade Católica do Rio Grande do Sul, 2002.

Sobre a aquisição do onset complexo. In: LAMPRECHT, R. R. (Org.). Aquisição fonológica do português: perfil de desenvolvimento e subsídios para terapia. Porto Alegre: Artmed, 2004.

SOUZA, Susana Silva de. O comportamento variável das vogais médias átonas: uma interface entre aquisição e variação. 2015. Tese (Doutorado em Letras) - Instituto de Letras e Artes, Pontifícia Universidade Católica do Rio Grande do Sul, 2015.

TEIXEIRA, Elizabeth. The acquisition of phonology in cases of phonological disability in Portuguese-speaking subjects. 1985. Tese (Doutorado em Letras), Universidade de Londres, Londres, 1985.

VASSOLER, Aline Mara de Oliveira. Coordenação gestual na produção de encontros consonantais em crianças com desenvolvimento típico e atípico. 2016. Tese (Doutorado em Estudos Linguísticos). Instituto de Biociências, Letras e Ciências Exatas, Universidade Estadual Paulista, 2016

YAVAS, Mehmet; HERNANDORENA, Carmen Lúcia Matzenauer; LAMPRECHT, Regina Ritter. Avaliação fonológica da criança. Porto Alegre: Artes Médicas, 1991.

Recebido em 26/01/2017.

Aceito em 16/06/2017. 